ORIGINAL ARTICLE

\title{
Myocardial ischaemia in children with sickle cell disease
}

\author{
M de Montalembert, C Maunoury, P Acar, V Brousse, D Sidi, G Lenoir
}

Arch Dis Child 2004;89:359-362. doi: 10.1136/adc.2003.027326

See end of article for authors' affiliations

......................

Correspondence to: Dr M de Montalembert, Service de Pédiatrie Générale, Hôpital Necker Enfants Malades, 149 rue de Sèvres, 75015 Paris, France; mariane. demontal@nck.ap-hopparis.fr

Accepted 27 July 2003
Background: The heart may be involved in children affected with sickle cell disease (SCD) via several mechanisms. Principally, chronic anaemia increases cardiac output and may cause left ventricular enlargement and cardiac insufficiency.

Aims: To investigate whether the heart also suffers from ischaemia in SCD, as has already been shown for other organs (bone, brain, etc), and to look for risk factors predisposing to this complication.

Methods: Twenty two children with SCD, and chest pain or ECG or echocardiographic signs (left ventricle dilation or hypokinesis) suggesting myocardial ischaemia were subjected to thallium-201 $\left({ }^{201} \mathrm{Tl}\right)$ single photon emission computed tomography (SPECT).

Results: Eight children had a normal SPECT, 14 an abnormal one. Myocardial perfusion defects were reversible in nine, fixed in five. Patients with perfusion defects tended to be older and have more severe disease. Five had had cardiac symptoms (episodes of cardiac failure in three, ventricular fibrillation in one, angina in one). Myocardial perfusion was reassessed after six months of hydroxyurea treatment in three patients, and was found to be improved.

Conclusions: Myocardial perfusion defects are present in children with SCD and may be demonstrated using SPECT. Hydroxyurea improved perfusion in three patients.
S ickle cell disease (SCD) is characterised by haemolytic anaemia and ubiquitous vessel occlusion by sickled red cells. Besides polymerisation of deoxyhaemoglobin S, adhesion of erythrocytes to endothelial cells contributes to altering vascular flow and to provoking vasoocclusion. Chronic and acute ischaemic complications are hallmarks of the disease. Surprisingly, the heart is not usually considered a high risk target organ, in particular in children. However, as many as $10-30 \%$ of adults suffer cardiac impairment, mostly left ventricular hypertrophy or congestive heart failure. ${ }^{1}$ Pathological studies have revealed associations with degenerative myocardial changes, interstitial fibrosis, and occlusion of intramural coronary arteries by aggregated sickle cells. ${ }^{2-5} \mathrm{~A}$ review of postmortem examinations of 70 patients (adults and children) with sickle cell disease performed between 1950 and 1981 at the University of Southern California found evidence of myocardial infarction and fibrosis in $17 \%{ }^{6}$ Classical cardiac abnormalities in children with SCD, heart murmur, and cardiomegaly, have been reported to be related to the volume overload effects of chronic anaemia, and the existence of an intrinsic myocardiopathy is disputed.

Recent major cardiac complications (fatal cardiac failure, severe arrhythmia, myocardial ischaemia) in three of our patients prompted us to explore cardiac status of our paediatric cohort with sickle cell disease. Besides the classical tools (ECG, echocardiography), we looked for myocardial ischaemia using single photon emission computed tomography (SPECT) in children selected according to clinical, ECG, and echocardiographic criteria. Twenty two patients met these criteria and underwent thallium-201 SPECT. Our initial aims were to assess the prevalence of myocardial ischaemia and to look for possible risk factors. Eight children in whom myocardial ischaemia was demonstrated were treated with hydroxyurea, and we could assess the efficacy of the treatment in three of them.

\section{METHODS}

A cohort of 300 children with sickle cell disease is being followed up in Necker Enfants Malades Hospital. All children receive a complete physical examination every three months, and are systematically asked about chest pain. Chest roentgenography is not systematic in our follow up, and is performed only in case of heart murmur or chest pain, and when patients are hospitalised. ECG is performed in case of heart murmur, chest pain, or cardiomegaly. Echocardiography is performed in children with heart murmur and/or cardiomegaly.

In this study, children with chest pain, heart failure, abnormal ECG, left ventricular dilatation, or hypokinetic left ventricle were selected for myocardial perfusion studies. Twenty two children met one or more of these criteria. Twelve were male and 10 female; mean age was 11.24 (1.04) years (range 3-19). Twenty one had homozygous sickle cell disease (SS), one was $S / \beta_{0}$-thalassemic. Two children (patients 6 and 22 in tables 1 and 2) had a history of stroke. Patient 6, aged 10 years, had been on regular transfusion for five years, and received daily iron chelation (ferritin $1100 \mathrm{ng} /$ $\mathrm{ml}$ ). Patient 22, aged 11 years, had a stroke six months before SPECT. She has been transfused monthly since the accident (ferritin level at SPECT: $500 \mathrm{ng} / \mathrm{ml}$ ). She received bone marrow transplantation some weeks after cardiac evaluation. Patients 9, 16, and 18 (aged 5, 4, and 3.5 years, respectively), had had episodes of cardiac failure. Seven patients had had chest pain, typical of angina in a 19 year old girl. Twelve patients had ECG abnormalities. Fourteen had left ventricular enlargement.

These 22 patients underwent ${ }^{201} \mathrm{Tl}$ SPECT after stress, and again three hours later after reinjection, using a single head gamma camera equipped with a low energy all purpose collimator. A dose of ${ }^{201} \mathrm{Tl}$ was injected at peak exercise or during the pharmacological or mixed stress testing (dose $(\mathrm{MBq})=$ weight $(\mathrm{kg}) \times 1.5)$. Pharmacological stress testing (using dipyridamole) was systematically used before the age of 6 years. In older children, pharmacological or exercise

Abbreviations: ECG, electrocardiography; ERNA, equilibrium radionuclide angiography; LVEF, left ventricular ejection fraction; SCD, sickle cell disease; SPECT, single photon emission computed tomography 
Table 1 Results: children with normal myocardial perfusion

\begin{tabular}{|c|c|c|c|c|c|c|c|c|}
\hline $\mathrm{Pt}$ & Age (y) & $\mathrm{Nb} \mathrm{VOC} / \mathrm{y}$ & ACS other & $\mathrm{Hb}(\mathrm{g} / \mathrm{l})$ & Chest pains & ECG & Echocardiography & Stress testing \\
\hline 1 & 6 & 0 & 0 & 67 & - & Abnormal & LV dilatation & - \\
\hline 2 & 11 & ND & 0 & 80 & - & Normal & Normal & + \\
\hline 3 & 9 & 0 & 0 & 85 & + & Abnormal & Normal & - \\
\hline 4 & 9 & 0 & 0 & 71 & - & Normal & LV dilatation & - \\
\hline 5 & 6 & 1.5 & 0 & 65 & + & Abnormal & LV dilatation & - \\
\hline 6 & 10 & 0 & 0 stroke & 96 & - & Normal & Normal & - \\
\hline 7 & 12.5 & 0 & 0 & 94 & + & Normal & Normal & - \\
\hline 8 & 10 & ND & 0 & 75 & - & Normal & Normal & - \\
\hline
\end{tabular}

VOC, vasoocclusive crises; ACS: acute chest syndrome; LV, left ventricular; ND, not determined.

testing (using progressive stages of 10 to 20 watts for 2 minutes until heart rate reaches $190 / \mathrm{min}$ ), or mixed testing was performed. Another dose of ${ }^{201} \mathrm{Tl}$ was reinjected before the redistribution acquisition $($ dose $(\mathrm{MBq})=$ weight $(\mathrm{kg}) \times$ $0.5)$. No patient required sedation. The matrix size format was $64 \times 64$. Starting from the left posterior oblique position to right anterior oblique position, 30 projections over $180^{\circ}$ were collected, 30 seconds per step.

The left ventricular ejection fraction (LVEF) was assessed by equilibrium radionuclide angiography (ERNA) at rest on the same day, using the gamma camera. The matrix size format was $64 \times 64$. Left anterior oblique and lateral views were taken, 5 million counts per view.

Haemoglobin $(\mathrm{Hb})$ levels and pulse oxymetry $\left(\mathrm{SpO}_{2}\right)$ (using a Nellcor N-395) (Nellcor Inc., Hayward, CA, USA) were measured on the same day, or within one week when SPECT was performed (no blood transfusion was given between these measurements and SPECT). The mean number of hospitalised vasoocclusive crises per year was evaluated from the medical records of the past three years for 19 patients, but could not be calculated for the remaining three. For all patients we also recorded the histories of acute chest syndromes (defined as acute respiratory illness with radiographic findings consistent with consolidation of the $\operatorname{lung}(\mathrm{s}))$.

Patient characteristics were compared using Student's $t$ test.

\section{RESULTS}

Tables 1 and 2 summarise the results.

\section{Myocardial perfusion studies}

Myocardial perfusion was abnormal in 14 of 22 patients, and normal in eight. In the 14 patients with abnormal perfusion, nine had reversible defects, and five had fixed defects (fig 1).
Mean LVEF was $61.7 \pm 8.8 \%$ and was not correlated with myocardial perfusion, left ventricular dilatation, or $\mathrm{Hb}$ level.

\section{Risk factors}

Mean age, $\mathrm{Hb}$ level, $\mathrm{SpO}_{2}$, and mean number of vasoocclusive crises/year did not differ significantly between normal SPECT and abnormal SPECT groups (table 3). However, children with perfusion defects tended to be older ( $12.7 \vee 9.2$ years, $\mathrm{p}=0.09)$, and have more severe diseases.

\section{Course}

Data for the first two patients included in this series (patients 9 and 10) have already been reported. ${ }^{8}$ Patient 9 had her first acute cardiac failure when she was 3 years old.

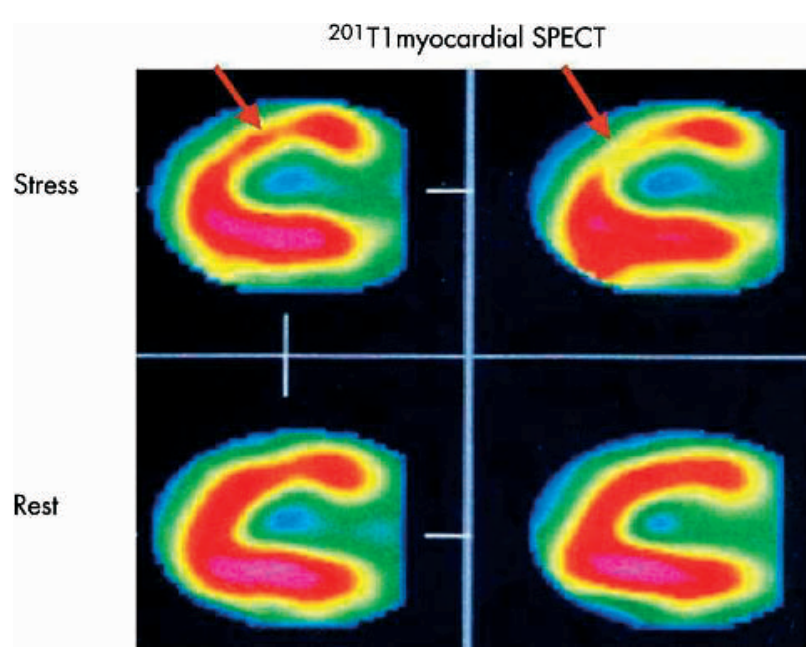

Figure $1{ }^{201} \mathrm{Tl}$ myocardial SPECT: reversible defect in the anterior wall, left ventricular cavity dilated.

Table 2 children with abnormal myocardial perfusion

\begin{tabular}{|c|c|c|c|c|c|c|c|c|c|c|}
\hline $\mathrm{Pt}$ & Age $(y)$ & $\mathrm{Nb} \mathrm{VOC} / \mathrm{y}$ & ACS other & $\mathrm{Hb}(\mathrm{g} / \mathrm{l})$ & Chest pains & ECG & Echo & $\begin{array}{l}\text { Stress } \\
\text { testing }\end{array}$ & Defect & Treatment outcome \\
\hline 9 & 5 & 0 & 0 & 80 & Heart failure & Abnormal & LV dilatation & + & Reversible & Death \\
\hline 10 & 16.5 & 0 & 0 & 75 & Arrhythmia & Abnormal & LV dilatation & - & Fixed & \\
\hline 11 & 16 & 1.5 & 1 & 66 & - & Abnormal & LV dilatation & + & Reversible & $\mathrm{HU}$ \\
\hline 12 & 17 & 0 & 0 & 59 & + & Normal & LV dilatation & + & Fixed & \\
\hline 13 & 16 & 1.5 & 0 & 77 & + & Abnormal & LV dilatation & - & Reversible & $\mathrm{HU}$ \\
\hline 14 & 14 & 0 & 0 & 55 & - & Abnormal & LV dilatation & - & Reversible & HU partial correction \\
\hline 15 & 10.5 & 0 & 0 & 67 & - & Abnormal & LV dilatation & - & Fixed & HU partial correction \\
\hline 16 & 4 & 0 & 0 & 90 & Heart failure & Normal & LV dilatation & + & Reversible & HU partial correction \\
\hline 17 & 18 & 6 & 1 & 70 & - & Abnormal & LV dilatation & + & Fixed & HU \\
\hline 18 & 3.5 & 1 & 2 & 75 & Heart failure & Normal & LV dilatation & - & Reversible & $\mathrm{HU}$ \\
\hline 19 & 19 & 3 & 3 & 85 & + & Abnormal & Normal & + & Reversible & $\mathrm{HU}$ \\
\hline 20 & 14 & 0 & 0 & 89 & + & & Normal & - & Reversible & \\
\hline 21 & 13 & ND & 0 & 74 & - & Abnormal & LV dilatation & - & Fixed & \\
\hline 22 & 11 & 1.5 & 4 stroke & 82 & - & Normal & normal & - & Reversible & BMT \\
\hline
\end{tabular}

VOC, vasoocclusive crises; ACS: acute chest syndrome; LV, left ventricular; ND, not determined; HU, hydroxyurea; BMT, bone marrow transplantation. 
Echocardiography showed an enlarged hypokinetic left ventricle (shortening fraction: $20 \%$ ). She was treated with diuretics and angiotensin converting enzyme inhibitors. Two years later, she had no signs of cardiac failure, but her left ventricle was still enlarged and hypokinetic. Stress testing was positive and ${ }^{201} \mathrm{Tl}$ SPECT showed an anteroseptal reversible perfusion defect. The child was then lost to follow up. She was hospitalised again at 7 years with severe cardiac failure (shortening fraction: 13\%) and died within days despite intensive cardiac resuscitation.

Patient 10 had ventricular fibrillation when he was 8 years old, followed the day after by constrictive chest pain, posterior subepicardial ischaemia, and severe heart failure. Q-T prolongation led to insertion of an implantable pacemaker. Eight years later, the patient had no new episode of arrhythmia and no signs of heart failure. ${ }^{201}$ Tl SPECT showed a fixed inferior perfusion defect, probably related to myocardial necrosis.

Among the 12 other patients with myocardial perfusion defects, patient 22, who had had a cerebrovascular infarct, received a bone marrow transplant in 2002, and patient 21 returned to Africa. Hydroxyurea treatment was begun in eight children who had myocardial perfusion defects and other complications of SCD: more than one hospitalised painful crisis/year (patients 11, 13, 17), severe anaemia (patients 14, 15), past history of acute chest syndromes (patients 18, 19), or a past history of acute cardiac failure (patient 16).

\section{Course under hydroxyurea treatment}

These eight patients were treated with hydroxyurea at a mean dosage of $20 \mathrm{mg} / \mathrm{kg} /$ day. SPECT was repeated after six months of treatment in three. Two patients had reversible defects that had improved, and one had a fixed defect, the size of which had decreased.

\section{DISCUSSION}

Our study shows myocardial perfusion defects in children with SCD, which can be demonstrated and followed with ${ }^{201} \mathrm{Tl}$ SPECT. This finding, which to our knowledge has never been reported in children with SCD, raises several questions. The first is the prevalence of these perfusion defects. In our paediatric population selected according to strict criteria (chest pain, heart failure, abnormal ECG, left ventricular dilatation, or hypokinetic left ventricle), this prevalence was as high as $14 / 22(63.6 \%)$. Prevalence depends clearly on the criteria used to perform SPECT. All the children in our series who had had an overt symptom of cardiac disease (heart failure episodes for patients 9, 16, 18; ventricular arrhythmia for patient 10; angina for patient 19) had perfusion defects. The relevance of ECG or echographic abnormalities may be more problematic to interpret in black children and adolescents, since some changes are considered to be nonspecific. ${ }^{2}$ However, we noted that more children had an abnormal ECG (9/14) and left cardiac enlargement (11/14) in the group with hypoperfusion than in the group with normal perfusion (who had respectively $3 / 8$ and $3 / 8$ ECG and

\begin{tabular}{llll} 
Table 3 & Patient & \multicolumn{3}{c}{ characteristics according to ${ }^{201} \mathrm{Tl}$ SPECT } \\
\hline & Normal SPECT & Abnormal SPECT & $\mathbf{p}$ \\
\hline $\mathrm{n}$ & 8 & 14 & \\
$\mathrm{Age}(\mathrm{y})$ & $9.2 \pm 2.3$ & $12.7 \pm 5.2$ & 0.09 \\
$\mathrm{Hb}(\mathrm{g} / \mathrm{l})$ & $79 \pm 11$ & $74 \pm 10$ & 0.36 \\
$\mathrm{SpO}_{2}(\%)$ & $97.5 \pm 2.1$ & $96.5 \pm 2.3$ & 0.48 \\
Vasoocclusive & $0.25 \pm 0.61$ & $1.11 \pm 1.7$ & 0.26 \\
crises/y & & & \\
\hline
\end{tabular}

echographic abnormalities). Criteria indicating when to perform SPECT will certainly need to be further debated. It is noteworthy that myocardial perfusion defects have also been reported using ${ }^{201} \mathrm{Tl}$ SPECT in patients aged over 18 who had chest pain of at least 30 minutes during pain episodes, since four of six patients in whom SPECT was performed had focal perfusion defects. All four also had ischaemic appearing ST-T abnormalities. ${ }^{10}$

Our first analysis did not show significant risk factors that could pinpoint a population more prone to heart disease, since age, $\mathrm{Hb}$ level, $\mathrm{SpO}_{2}$, and the mean number of hospitalised vasoocclusive crises/year were not statistically different in children with or without perfusion defects. Among the two children with a past history of cerebrovascular disease, one had a normal SPECT (patient 6, who had received regular transfusions for five years), and the other had an abnormal SPECT (patient 22, who had a recent stroke and received bone marrow transplantation some weeks after SPECT). The children with perfusion defects were, however, older than those with normal SPECT, and there was a tendency towards a lower $\mathrm{Hb}$ level and a greater number of vasoocclusive crises in the group with perfusion defects. This difference will perhaps reach significance when a greater number of children are studied.

Other questions concern the significance of myocardial perfusion defects in children with SCD and the possible course of these abnormalities. Considering the importance of vasoocclusion in SCD, related to polymerisation of sickle haemoglobin, adherence between sickle and endothelial cells, and vascular tone abnormalities, it is not surprising to find that ischaemia does not spare the heart in SCD. These findings agree with anatomopathological evidence of myocardial infarction and fibrosis at postmortem examination. $^{2451112}$ No occlusion of the major coronary arteries was found in these series, which strongly suggests that it is the microcirculation that is involved. It is too soon to determine the possible course of myocardial perfusion defects, but we can note that patients 9, 16, and 18 had had overt heart failure, fatal in patient 9 at 7 years of age, and that it is reasonable to relate the ventricular fibrillation episode to the ischaemic myocardial changes in patient 10 . We must also remember that, besides myocardial hypoperfusion, SCD children have other factors that may impair cardiac function, such as chronic anaemia and increased cardiac output. Cardiac enlargement is a well known observation in children with $\mathrm{SCD}^{17^{13} 14}$ and has been found to be related to the severity of anaemia and percentage of $\mathrm{HbS}^{7{ }^{13}}$ Our findings are in favour of a specific ischaemic cardiomyopathy that could worsen the consequences of the increased cardiac output. Furthermore, some children receive very frequent transfusions, and are exposed to the cardiac toxicity of iron overload.

For about 10 years, hydroxyurea has been recognised as having a beneficial effect on the prognosis of sickle cell disease in adults ${ }^{15}$ and in children. ${ }^{16-18}$ This cytostatic drug probably alleviates the severity of the disease via a number of pathways: induction of fetal haemoglobin synthesis (which has a sparing effect on polymerisation of haemoglobin S), reduction in reticulocyte adhesion to vascular endothelium, ${ }^{19}$ modulation of inflammatory processes, induction of $\mathrm{NO}$ synthesis, ${ }^{20}$ etc. Although we do not yet have evidence that hydroxyurea acts directly on vascular remodelling, all these indirect arguments led us to hypothesise that hydroxyurea could at least partially correct the hypoperfusion; we therefore decided to administer it to selected children. However, due to our uncertainty about the long term effects of this cytostatic drug, we restricted this treatment to children for whom we also had other grounds for considering hydroxyurea treatment (for example, 1-2 hospitalised painful crises/ 
year, severe anaemia). Interestingly, the first three children treated with hydroxyurea for whom we reassessed myocardial perfusion showed improvement. We intend to continue monitoring SPECT in the other children who are currently being treated with hydroxyurea. If we confirm that hydroxyurea improves myocardial perfusion, we will suggest giving this drug to all children in whom perfusion defects are found, considering that the hypothetical risk of malignancy will be counterbalanced by a decrease in the risk of myocardial impairment. ${ }^{21}$ It would be of interest to evaluate whether patients with silent ischaemia could be identified, as they would benefit more from earlier treatment.

In conclusion, we report that myocardial perfusion abnormalities can be demonstrated using ${ }^{201} \mathrm{Tl}$ SPECT in children affected with SCD. Those with myocardial perfusion abnormalities tend to be older, have a lower Hb level, and more frequent vasoocclusive crises. Perfusion defects may be reversible or fixed and may lead to cardiac failure or arrhythmia. Improvement in cardiac perfusion was observed in three children of our series who were treated with hydroxyurea.

Finally, we postulate that cardiac impairment is underestimated in children because it is under-investigated. Chest pain is usually attributed to bone infarcts and cardiomegaly to chronic anaemia. As a result of our findings, we now intend to perform ECG systematically in cases of chest pain and/or cardiac enlargement. For the moment, we plan to keep the same clinical, ECG, and echographic criteria for deciding whether or not to perform SPECT. If we confirm in more cases that hydroxyurea in fact improves cardiac perfusion, we will consider that the hypothetical risk of malignancy will be counterbalanced by a decrease in the risk of myocardial impairment.

\section{Authors' affiliations}

M de Montalembert, V Brousse, G Lenoir, Service de Pédiatrie Générale, Hôpital Necker Enfants Malades, 149 rue de Sèvres, 75015 Paris, France

C Maunoury, Service de Médecine Nucléaire, Hôpital Necker Enfants Malades, 149 rue de Sèvres, 75015 Paris, France

P Acar, D Sidi, Service de Cardiologie Pédiatrique, Hôpital Necker Enfants Malades, 149 rue de Sèvres, 75015 Paris, France

\section{REFERENCES}

1 Covitz W. Cardiac disease. In: Embury SH, Hebbel RP, Mohandas N, Steinberg $\mathrm{MH}$, eds. Sickle cell disease: basic principles and clinical practice. New York: Raven Press, 1994:725-34.

2 Uzsoy NK. Cardiovascular findings in patients with sickle cell anemia. Am J Cardiol 1964;13:320-8.

3 Oliveira E, Gomez-Patino N. Falcemic cardiomyopathy. Am J Cardiol 1963;11:686-8.

4 Gerry JL, Bulkley BH, Hutchins GM. Clinicopathological analysis of cardiac dysfunction in 52 patients with sickle cell anemia. Am J Cardiol 1978;42:211-16.

5 Rubler S, Altman Fleischer R. Sickle cell states and cardiomyopathy. Am J Cardiol 1967;19:867-73.

6 Martin C, Cobb C, Johnson C, et al. Cardiovascular pathology in sickle cell disease. J Am Coll Cardiol 1983;1:723.

7 Lester LA, Sodt PC, Hutcheon N, et al. Cardiac abnormalities in children with sickle cell anemia. Chest 1990;98:1169-74.

8 De Pontual L, Acar P, de Montalembert M, et al. L'ischémie myocardique: une complication méconnue de la drépanocytose de l'enfant. A propos de 2 observations. Arch Pédiatr 1999;6:178-81.

9 Mansi IA, Rosner F. Myocardial infarction in sickle cell disease. J Natl Med Assoc 2002;94:448-52.

10 Norris S, Johnson CS, Julian Haywood L. Sickle cell anemia: does myocardial ischemia occur during crisis? J Natl Med Assoc 1991;83:209-13.

11 James TN. Homage to James B. Herrick. A contemporary look at myocardial infarction and at sickle cell heart disease. Circulation 2000;101:1874-87.

12 Martin CR, Johnson CS, Cobb C, et al. Myocardial infarction in sickle cell disease. J Natl Med Assoc 1996;88:428-32.

13 Covitz W, Espeland M, Gallagher D, et al. The heart in sickle cell anemia. The cooperative study of sickle cell disease (CSSCD). Chest 1995;108:1214-19.

14 Rees AH, Stefadouros MA, Strong WB, et al. Left ventricular performance in children with homozygous sickle cell anaemia. Br Heart J 1978;40:690-6.

15 Charache S, Terrin ML, Moore RD, et al. Effect of hydroxyurea on the frequency of painful crises in sickle cell anemia. N Engl J Med 1995;332:1317-22.

16 Kinney TR, Helms RW, O'Branski EE, et al. Safety of hydroxyurea in children with sickle cell anemia: results of the HUG-KIDS study, a phase I:II trial. Blood 1999;94:1550-4.

17 De Montalembert $M$, Bégué $P$, Bernaudin $F$, et al. Preliminary report of a toxicity study of hydroxyurea in sickle cell disease. Arch Dis Child 1999:81:437-9.

18 Ferster A, Tahriri P, Vermylen C, et al. Five years of experience with hydroxyurea in children and young adults with sickle cell disease. Blood 2001;97:3628-32.

19 Styles LA, Lubin B, Vichinsky E, et al. Decrease of very late activation antigen-4 and $C D 36$ on reticulocytes in sickle cell patients treated with hydroxyurea. Blood 1997;89:2554-9.

20 Gladwin MT, Shelhamer JH, Ognibene FP, et al. Nitric oxide donor properties of hydroxyurea in patients with sickle cell disease. $\mathrm{Br} J$ Haematol 2002;1 16:436-44

21 De Montalembert $M$, Davies SC. Is hydroxyurea leukemogenic in children with sickle cell disease? Blood 2001;98:2878-9.

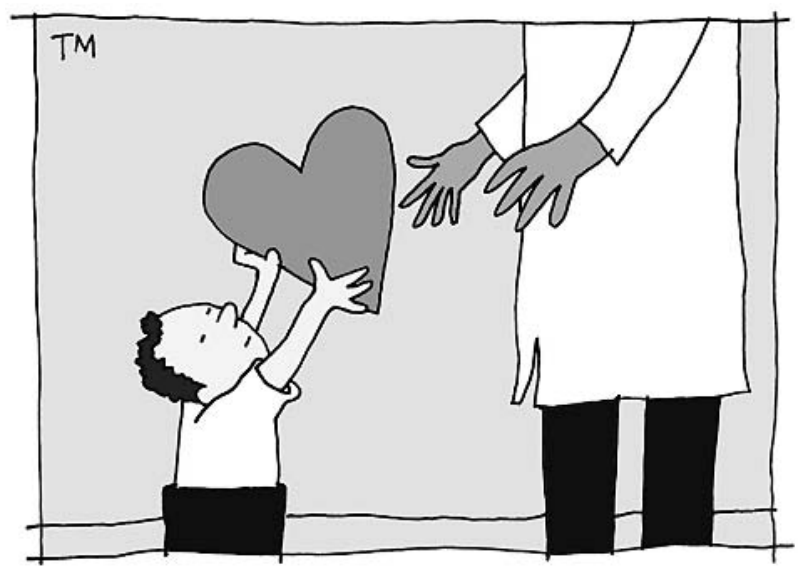

